\title{
Sustainability Analysis of Different Types of Power Plants Using Multi-Criteria Decision Analysis Methods
}

\author{
Anik Saha Dipto*, Md Abdullah Al Bari and Shadman Tahsin Nabil \\ Department of Mechanical Engineering, Khulna University of Engineering \& Technology, Khulna-9203, BANGLADESH
}

Received: September 14, 2020, Revised: September 29, 2020, Accepted: September 30, 2020, Available Online: October 03, 2020

\begin{abstract}
Power requirements are growing day by day, and more power plants are being constructed all over the world. Now the goal has been to look for more sustainable sources of electricity. Sustainability of power plants is a complicated concept and depends on various criteria and sub-criteria. By evaluating them separately creates a complex problem. For this here Multi-Criteria Decision Analysis (MCDA) methods are used for overall assessment and make a sustainability index for seven mostly used power plants. Consideration is taken to both renewable and non-renewable sources. The goal is divided into three basic criteria (i.e. technology, safety \& sustainability, economy) and each criterion is further sub-divided into different sub-criteria. The data is collected from various sources and then analyzed using AHP and PROMETHEE methods. The result indicate renewable sources are typically advantageous over nonrenewable sources. In certain cases, nuclear has some benefits over other non-renewable energy sources.
\end{abstract}

Keywords: Sustainability; Power plants; MCDA; AHP; PROMETHEE.

This work is licensed under a Creative Commons Attribution-Non Commercial 4.0 International

\section{Introduction}

Sustainability can be termed as a process that satisfies the present needs of people without hampering the generation process for future generations. The sustainability concept is based on three main pillars: social, economic and environmental. The term sustainability was first brought up by the Brundtland Report in 1987. There are goals and visions for this sustainability which take the society to a brighter future [1].

As the need of electrical power is day by day increasing there should be emphasis given on the power sector. Power plant building without any pre-analysis or pre-planning is pretty much unwise by considering future needs of power. As power can be generated from different sources it is wise to analyze which power source to be chosen for more effective performance of the power plant not just in the present but also in the future. So as for this, the sustainability term comes in work. The sustainability of power plants means selecting the appropriate power plant considering different condition and selecting a power plant for both present and future needs.

In Bangladesh defining and understanding the term sustainability for power plants has become very important nowadays because a rumor has been built up whether the construction of new power plants like Matarbari coal-based power plant, Rampal coal-based power plant, Rooppur nuclear power plant etc. are sustainable or not. And why these fuel sources are being chosen instead of other sources likewise gas, oil, wind, solar, etc. The sustainability index can answer this sort of question about their importance in the present and future periods. As being a developing country Bangladesh should keep eye on the sustainable development of power source as the requirement of power will increase exponentially day by day.

For developing a sustainability index for different types of power plants at first the goal is to define sustainability in terms of parameters which can be measured and expressed by data. To do that sustainability is divided into three main criteria as technology, safety and sustainability, and economy [2, 3]. These three criteria are then subdivided into eleven sub-criteria. Now to make a sustainability index, multi-criteria decision analysis (MCDA) method is used. MCDA is the collection of decisionmaking methods that helps a decision-maker to select a decision based on different data. The data are collected from trusted sources and after analyzing the data a goal can be achieved. Different types of method can be used in order to complete the final analysis. Different types of MCDA methods are named as AHP, ANP, MAUT, MACBETH, PROMETHEE, ELECTRE, TOPSIS etc. These are the most commonly used methods for multi-criteria decision analysis. The decision-making problems can be of different types like, wise ranking problem, rating problem, case problem, etc. But in this analysis only rating and ranking type analysis is done. So, for this research AHP and PROMETHEE methods are selected to carry out sustainability analysis for different types of power plants.

\section{Methodology}

\subsection{Multi-criteria decision analysis}

MCDA methods are designed in such a way that it helps people deciding of complex problems which have many alternatives way of solving. When subjective information are loaded in the MCDA system it uses it to solve the problem. The decision-maker is in control of the system and supplies the necessary information to the system. MCDA has a quite large range of applications. Mathematical, social science, informatics, management, marketing, and economics problems can be solved by the MCDA method. Four types of problems are solved widely by using the MCDA method. Ranking problems, sorting problems, choice problems, description problems. In this paper we will use the MCDA to solve ranking and choice problems. For solving choice and ranking problems different types of the MCDA method has been designed. Some of them are, 
Table 1 Different ranking and choice-making processes of MCDA

\begin{tabular}{cc}
\hline Method Name & Full meaning \\
\hline AHP & Analytic Hierarchy Process \\
ANP & Analytic Network Process \\
MAUT & The Multi-Attribute Utility Theory \\
& Measuring Attractiveness Through a \\
MACBETH & Categorical-based Evaluation \\
& Technique \\
PROMETHEE & Preference Ranking organization \\
& method for enrichment evaluation \\
\hline
\end{tabular}

In our evaluation of the sustainability of different types of powerplants, we have used three methods that are AHP, PROMETHEE, and TOPSIS. For these methods, the alternatives are first selected. There are a total of seven alternatives that are, Coal based plant, Nuclear power plant, Oil based power plant, Gas power plant, Solar power plant, Hydro power plant, and Wind power plant. The main goal is to find the most sustainable power plat for electricity generation. This main goal is achieved by defining sustainability into some criteria. Then the criteria are further sub-divided into some specific sub-criteria.

After each criterion has been defined each of them are needed to be analyzed by the presence of proper data and method and thus a final result can be achieved by MCDA method.

The AHP and PROMETHEE both methods are independent of each other. Only one method is enough to get a suitable result, but here to methods are used in order to see how much the result in individual methods vary from one another.

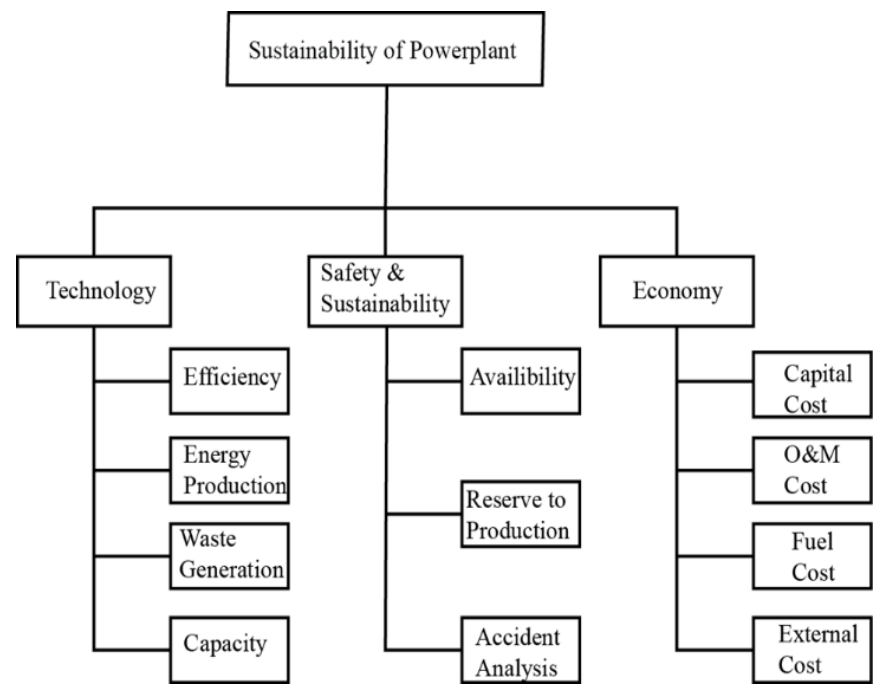

Fig. 1 The analysis of most sustainable powerplant problem by MCDA method

\subsubsection{Analytic hierarchy process}

AHP is a method that solves a problem by dividing it into some criteria and sub-criteria and analysis it. AHP helps by giving a simple solution to any complex problem. AHP divides a complex problem into simple parts so by solving and analyzing these simple parts together, the whole solution can be acquired. The problems are needed to be structured and these structured problems are needed to compare pairwise for getting a result [4]. A hierarchy is designed to solve the problem. The upper element is the final decision that is to be taken, the second level is the criteria and the criteria is sub divided into some sub-criteria. The sub-criteria can also be sub divided if needed. In our case, we have divided our goal sustainability analysis of power plants into three criteria and eleven sub-criteria.

After the criteria and sub-criteria are designated then the priority of each alternatives is needed to be calculated by a priority matrix. A priority scale has been designated by American School and this is used in AHP method [5].

Table 2 The scale of AHP

\begin{tabular}{cc}
\hline Degree of priority & Definition \\
\hline 1 & Equal importance \\
3 & Moderate importance \\
5 & Strong importance \\
7 & Very strong importance \\
9 & Extreme importance \\
\hline
\end{tabular}

The AHP uses the pairwise comparison between the alternatives. The comparison is done manually and then the data is collected in a matrix form. The more the number of alternatives the more effort is needed to be given. If there are $n$ alternatives the number of comparisons for each criterion is $\left(n^{2}-n\right) / 2 n^{2}$, total comparison that is available to a matrix. Each evaluation with alternative with same alternative is regarded as 1. Each alternative is been compared with one another and a comparison matrix is been built. If we take in consideration the technology criteria and efficiency coefficient sub-criteria for AHP analysis first the data is collected, here for sample analysis the efficiency coefficient sub-criterion has been taken into account.

\subsubsection{PROMETHEE}

The PROMETHEE is also an alternative based choice making method that uses data for analysis and is less manual than AHP. This method has three basic steps:

1. Preference degree calculation for each alternative for each criterion and sub-criterion;

2. The uni-criterion flow analysis;

3. The global flow determination.

For the first step of calculation the data should be unitarized. For this purpose the maximum and minimum value in each data set is to be determined and for beneficial criteria,

$$
x_{i}=\frac{x(i)-\min (i)}{\max (i)-\min (i)}
$$

For non-beneficial criterion,

$$
x_{i}=\frac{\max (i)-x(i)}{\max (i)-\min (i)}
$$

where,

$x_{i}=$ Value of any alternative for any sub-criterion

$\max (i)=$ Maximum value of an alternative in that subcriterion

$\min (i)=$ Minimum value of an alternative in that subcriterion

Then the values each alternatives value in a criterion should be subtracted with each other to get a value and then the negative value are been neglected. Then each sub-criterion should be divided with its own weight. After that each alternative are summed and value of the global criterion preference matrix is got. 
Next, the positive and negative flow is calculated. As it is hard to draw conclusions from preference degrees the criterion preference degree is summarized in a way that is a positive flow or noncriterion leaving and negative flow or noncriterion entering and the net flows are calculated for each alternative. The noncriterion positive flows indicates how an alternative is preferred over all other alternatives. The higher the positive flow is the more preferred the alternative is. On the other hand, the negative flows indicate the average behavior of all alternatives. They show how other alternatives are preferred than this alternative. By considering both positive and negative flow net flow is calculated. The net score lies between -1 to 1 . There is two ranking method of PROMETHEE in this study PROMETHEE-II has been used as PROMETHEE-I doesn't give any comparison value [6].

\subsubsection{The Gaia plane}

The Gaia plane is an imaginary plane that contains aspects of a decision problem in two dimensional planes. In this Gaia plane, actions are represented by bullets and criteria by arrows. The position of the actions gives the decision-maker some idea about their similarities. The relative position of criterion indicates the correlation and anti-correlation between criterions. The closer are more correlated. The Gaia plane helps decisionmaker to visualize conflicting point in the process. The length of the criterion indicates the power of the generated data. So, all the information can be got from the Gaia plane in the PROMETHEE method [7].

\section{Data}

All the data are collected from different free sources available. Here is the data for different sub-criteria:

\subsection{Technology}

For powerplant technological factors are much important to take into consideration. Technology criterion is sub-divided into four sub-criteria. They are efficiency co-efficient, energy production rate, waste generation and capacity.

Table 3 Efficiency coefficient of 7 types of power plant [8].

\begin{tabular}{cc}
\hline Types of powerplant & Efficiency coefficient \\
\hline Coal & 39.4 \\
Nuclear & 33.5 \\
Oil & 37.5 \\
Gas & 43.4 \\
Hydro & 80.0 \\
Solar & 9.40 \\
Wind & 35.0 \\
\hline
\end{tabular}

\subsubsection{Efficiency co-efficient}

The efficiency coefficient can be defined as the ratio of the energy output to input energy. Efficiency which has relatively high useful energy can be improved by high plant reliability for economic benefit. Understandably, high efficiency is consistent with high plant reliability and low cost of electricity is economically beneficial for powerplant management [8]. As no machine cannot give a unit efficiency, there will be losses in every powerplant. Here presented a statistical analysis done by IAEA 2002 that shows different powerplants efficiency. It shows that hydropower has the most efficiency co-efficient amongst all the sources and solar has the least. Coal has more efficiency coefficient than nuclear and oil but gas has an upper hand on coal.

\subsubsection{Energy production}

Energy production rate can be defined as the amount of energy produced by per $\mathrm{kg}$ of fuel burning in per hour time. The calorimetric analysis is used to determine the energy production rate of any fuel [9]. A report published by the University of Washington, gives data on energy production of different sources if other factors are constant. It can be seen that gas has the more energy production rate than the other sources and can be more beneficial in selection. Nuclear is more efficient than the other non-renewable and the renewable sources have infinity amount of energy production.

Table 4 Energy production of different power plant [9].

\begin{tabular}{cc}
\hline Types of power plant & Energy production (KW.hr/lb.) \\
\hline Coal & 4.4 \\
Nuclear & $10.6^{*} 10^{\wedge} 3$ \\
Oil & 6.67 \\
Gas & 19.07 \\
Hydro & Infinity \\
Solar & Infinity \\
Wind & Infinity \\
\hline
\end{tabular}

\subsubsection{Waste generation}

In this evaluation, the waste generation is taken as the $\mathrm{CO} 2$ emission from the different power plants. Measuring the lifecycle greenhouse gas emissions involves measuring the global warming potential of electrical energy sources by assessing the life-cycle of each source. The findings are described in units of potential for global warming per unit of produced electrical energy from that source. Waste generation can be expressed in gram equivalent of $\mathrm{CO} 2$ in per $\mathrm{KW}$ of energy production. Thomas Bruckner in an article called "Mitigation of Climate Change" published the for $\mathrm{CO} 2$ emission from the different power plants [10]. Coal powerplants emit the most amount of carbon-die-oxide and nuclear and wind are the cleanest source of energy.

Table 5 Waste generation from different powerplants [10].

\begin{tabular}{cc}
\hline Types of power plant & $\begin{array}{c}\text { Waste generation } \\
(\mathrm{gCO} 2 \mathrm{eq} / \mathrm{kWh})\end{array}$ \\
\hline Coal & 820 \\
Nuclear & 12 \\
Oil & 520 \\
Gas & 490 \\
Hydro & 24 \\
Solar & 48 \\
Wind & 12 \\
\hline
\end{tabular}

\subsubsection{Capacity factor}

The capacity factor is a dimensionless parameter used in the evaluation of power plants. The capacity factor of a powerplant can be defined as the actual amount of energy produced in a certain interval of time and the maximum energy that could have been produced by running the power plant at full power at that time. This parameter or criteria has great importance in power plant evaluation. The capacity generally is less than $100 \%$, as machines need to do periodic maintenance and sometimes 
corrective maintenance too. The performance of a power plant greatly depends on its capacity. It is a beneficial criterion. On a report published by EIA, 2019 different powerplant capacity was analyzed [11]. It has been found that nuclear power plant has the height capacity and the solar has the lowest.

Table 6 Capacity factor of different power plant [11].

\begin{tabular}{cc}
\hline Types of power plant & Capacity factor \\
\hline Coal & 85 \\
Nuclear & 90 \\
Oil & 30 \\
Gas & 87 \\
Hydro & 50 \\
Solar & 20 \\
Wind & 38 \\
\hline
\end{tabular}

\subsection{Safety and sustainability}

In the evaluation of powerplants, the safety of human life and the plant equipment must be taken into consideration. Also, the sustainability of energy sources should be ensured. The subcriteria that are been in this criterion is availability, reserve to production ratio and accidental death analysis.

\subsubsection{Availability}

In the case of powerplant, the availability describes the time period that a power plant is able to generate electricity over a certain period of time. A power plant can be out of service due to maintenance or repair [12] or due to weather conditions like lack of sunlight or wind etc. [13]. The equipment quality, maintenance, types of fuel used and how the operation is done in the power plant greatly affects the availability of the power plant. If other factors are equal power plants which run more do have a higher value of availability. IAEA published a report in 2002 [14] that shows availability of various types power plants. Here it can be seen that nuclear has the most availability on the other hand solar has the least once. Oil and gas dominate over coal power plant.

Table 7 Availability of different power plant [14].

\begin{tabular}{cc}
\hline Types of power plant & Availability \\
\hline Coal & 85.4 \\
Nuclear & 96 \\
Oil & 92 \\
Gas & 91 \\
Hydro & 50 \\
Solar & 20 \\
Wind & 38 \\
\hline
\end{tabular}

\subsubsection{Reserve to production ratio}

The reserve to production ratio is the ratio of the currently available amount of fuel to the annual consumption of each nonrenewable resources. When considering the fuel sources only well- known sources are taken into account. Different types of models are used in this case. Non-economic extraction of fuel is not considered as available sources. British petroleum publishes a report every year based on reserve to production ratio of every available non-renewable sources. Here from the BP report 2019 [15] all the data has been taken for 7 types of powerplants. Here it can be seen that all renewable sources have the maximum infinity reserve to production, oil has the most minimum resources compare to other. These values represent the current situation but new sources of energy are been discovered always.

Table 8 Rpr for different power plant [15].

\begin{tabular}{cc}
\hline Types of power plant & RPR \\
\hline Coal & 164 \\
Nuclear & 70 \\
Oil & 40.5 \\
Gas & 66.7 \\
Hydro & Infinity \\
Solar & Infinity \\
Wind & Infinity \\
\hline
\end{tabular}

\subsubsection{Accidental analysis}

One of the vital concerns in the power plant is to ensure the safety of the workers and the public. For this, the powerplant with the least amount of accidental deaths is preferable as human life is more superior to power generation. For the accidental analysis purpose, total amounts of deaths are taken into account until now from different power sources in different types of accidents. Organization for economic and co-operation development published a report that shows deaths from different power plants [16] The maximum amount of deaths are caused by coal-based power plant.

Table 9 Accidental deaths from different power plants [16].

\begin{tabular}{cc}
\hline Types of power plant & Accidental Death \\
\hline Coal & 36441 \\
Nuclear & 31 \\
Oil & 20218 \\
Gas & 2043 \\
Hydro & 29938 \\
Solar & 0 \\
Wind & 0 \\
\hline
\end{tabular}

\subsection{Economy}

For business purposes, the economy should be taken into concern for powerplants as the main purpose of a powerplant should produce energy at a lower cost. So for selecting the best powerplant all costs should be taken into account. The costs that are important in the powerplant economy are capital costs, the operation, and management cost, the fuel cost, the external cost, etc.

Table 10 Capital costs of different power plants [17].

\begin{tabular}{cc}
\hline Types of power plant & Capital Costs $(€ / \mathrm{KW})$ \\
\hline Coal & 3661 \\
Nuclear & 6016 \\
Oil & 1802 \\
Gas & 1079 \\
Hydro & 2752 \\
Solar & 7191 \\
Wind & 5446 \\
\hline
\end{tabular}

\subsubsection{Capital cost}

The capital cost can be regarded as the summation of land cost, the necessary cost for infrastructure and the necessary equipment costs that are needed to run the power plant. Labor costs needed to build the powerplant are not included here. EIA 
published a report in 2019, publishing the total capital cost needed to build the powerplant [17]. It can be seen that coal and nuclear have relatively high capital costs than others. Oil power plants have lowest capital costs among other electricity generation options.

\subsubsection{Operations and maintenance cost}

Wages of employees, energy funds, the products and service for power plant operation include the O\&M cost. Also, the management cost is included in this cost as it is very much necessary for proper maintenance for the prolonged serviceability of the power plant. Also, if any part of the power plant gets deuterated it is needed to be fixed. The operation management cost is divided into two sub categories; fixed O\&M cost and variable $O \& M$ cost. Fixed operation cost is the cost that is calculated yearly based and has no effect on the amount of energy produced and the variable cost is directly related to the amount of energy produced. The value of O\&M cost is got from the IAE report 2019 [17]. The variable O\&M cost are zero for renewable sources as while production they don't need extra maintenance.

Table 11 Fixed O\&M cost of different power plants [17].

\begin{tabular}{cc}
\hline Types of power plant & O\&M Cost $(€ / \mathrm{KWyr})$ \\
\hline Coal & 4.613 \\
Nuclear & 13.83 \\
Oil & 4 \\
Gas & 1.6 \\
Hydro & 4.75 \\
Solar & 9.7 \\
Wind & 12.5 \\
\hline
\end{tabular}

Table 12 Variable O\&M cost of power plants [17].

\begin{tabular}{cc}
\hline Types of power plant & O\&M Cost $(€ / \mathrm{KWyr})$ \\
\hline Coal & 4.48 \\
Nuclear & 2.36 \\
Oil & 5.67 \\
Gas & 2.54 \\
Hydro & 1.39 \\
Solar & 0 \\
Wind & 0 \\
\hline
\end{tabular}

Table 13 Fuel cost of different power plants [14].

\begin{tabular}{cc}
\hline Types of power plant & Fuel Cost $(€$ cent/KWyr $)$ \\
\hline Coal & 1.31 \\
Nuclear & 0.27 \\
Oil & 1.84 \\
Gas & 2.34 \\
Hydro & 0 \\
Solar & 0 \\
Wind & 0 \\
\hline
\end{tabular}

\subsubsection{Fuel cost}

Fuel is something that is burned and produces energy. For power plant economy it is always required the cheapest value fuel. The cheaper the fuel is the more economic benefit the plant has. Fuel releases energy from the chemical reaction and passes this energy to run the turbine and produces electric energy. The discharge is performed in such a controlled way that this energy can utilize to achieve maximum work. IAEA report 2002 gives a basic price value of all fuels [14]. It can be seen that renewable sources have less fuel cost and gas is the most expensive one.

\subsubsection{External cost}

These costs are categorized with the extra cost of health and the environment. It is not mixed with the cost of the generation of electricity. These external costs are related to the restoration of the negative side effects that happen on human health as well as the ecosystem during the operation power plant. They are calculated on the basis of the life cycle external cost of the powerplant. By report IAEA 2002 an overview data of different powerplants is got [14].

Table 14 External cost of different power plants [14].

\begin{tabular}{cc}
\hline Types of power plant & External Cost $(€$ cent/KWyr $)$ \\
\hline Coal & 8.4 \\
Nuclear & 0.49 \\
Oil & 6.75 \\
Gas & 2 \\
Hydro & 0.56 \\
Solar & 0.24 \\
Wind & 0.16 \\
\hline
\end{tabular}

\section{Results and discussion}

Here in this analysis two cases have been considered. Case 1 Global criterion and sub-criterion mean taking each criterion with equal importance and the relatively analyzing the subcriterion based on their relative importance. And case 2 means taking all sub criterion as equal. These cases are not constant, they are both independent. This case varies with time, location etc. So as for sample analysis two basic cases have been considered. Either one of the case can give suitable result.

\subsection{Analysis conditions and results by AHP}

For the analysis purpose different sample condition were taken by varying the weight of criterion. As by multiplying the weight factor with the priority factor the importance of each alternatives can be got. For analysis purpose two conditions are taken for every method.

\subsubsection{Case 1(Global sub-criterion)}

For this condition technology, safety \& sustainability and economy all the criteria have been considered with an equal weight of $33.33 \%$. Next for determining the weight of each subcriterion pairwise comparison is done. If the economy criterion is taken as an example every sub-criterion is compared with other pairwise and the pairwise value is got.

Table 15 Pairwise comparison of economy criteria

\begin{tabular}{ccccc}
\hline $\begin{array}{c}\text { Sub criterion } \\
\text { of Economy }\end{array}$ & $\begin{array}{c}\text { Capital } \\
\text { cost }\end{array}$ & $\begin{array}{c}\text { Operation \& } \\
\text { management } \\
\text { costs }\end{array}$ & $\begin{array}{c}\text { Fuel } \\
\text { costs }\end{array}$ & $\begin{array}{c}\text { External } \\
\text { costs }\end{array}$ \\
\hline $\begin{array}{c}\text { Capital cost } \\
\text { Operation \& } \\
\text { management } \\
\text { costs }\end{array}$ & 1 & 5 & 1 & 3 \\
$\begin{array}{c}\text { Fuel costs } \\
\text { External } \\
\text { Costs }\end{array}$ & $1 / 5$ & 1 & $1 / 5$ & $1 / 3$ \\
\hline
\end{tabular}


This is how every criterion is analyzed and a global subcriteria index is got by the process. As the pairwise comparison is easy and no exact data are not needed for determining the weight, this method is vastly used in the process of determining the weights. The global criteria mainly give information about these three equal criteria. A global ranking of $100 \%$ of power plant evaluation different weight of sub-criteria is got which is shown on Table 16.

Table 16 Global Criterion and sub-criterion weight

\begin{tabular}{|c|c|c|c|c|c|}
\hline \multicolumn{6}{|c|}{ Sustainability of power plant ( $100 \%)$} \\
\hline \multicolumn{2}{|c|}{$\begin{array}{c}\text { Technology } \\
(33.33 \%)\end{array}$} & \multicolumn{2}{|c|}{$\begin{array}{c}\text { Safety and } \\
\text { sustainability } \\
(33.33 \%)\end{array}$} & \multicolumn{2}{|c|}{ Economy $(33.33 \%)$} \\
\hline $\begin{array}{c}\text { Energy } \\
\text { coefficient }\end{array}$ & $2.33 \%$ & Availability & $4.30 \%$ & $\begin{array}{c}\text { Capital } \\
\text { Costs }\end{array}$ & $12.92 \%$ \\
\hline $\begin{array}{c}\text { Waste } \\
\text { Generation }\end{array}$ & $17.5 \%$ & $\begin{array}{l}\text { Reserve to } \\
\text { production } \\
\text { ratio }\end{array}$ & $24.71 \%$ & $\begin{array}{c}\text { Operation \& } \\
\text { Management } \\
\text { Costs }\end{array}$ & $2.20 \%$ \\
\hline $\begin{array}{c}\text { Energy } \\
\text { Production }\end{array}$ & $9.00 \%$ & $\begin{array}{l}\text { Accidental } \\
\text { death } \\
\text { analysis }\end{array}$ & $4.30 \%$ & Fuel Costs & $12.92 \%$ \\
\hline Capacity & $4.55 \%$ & & & $\begin{array}{c}\text { External } \\
\text { Costs }\end{array}$ & $5.91 \%$ \\
\hline
\end{tabular}

By applying global criterion and sub-criterion weight for different powerplants the final results are got by AHP analysis. It can be seen that the wind power plant is more preferable than the other power plants and hydro is also same preferability like wind. Oil is less preferable than the other sources and nuclear has an advantage on coal.

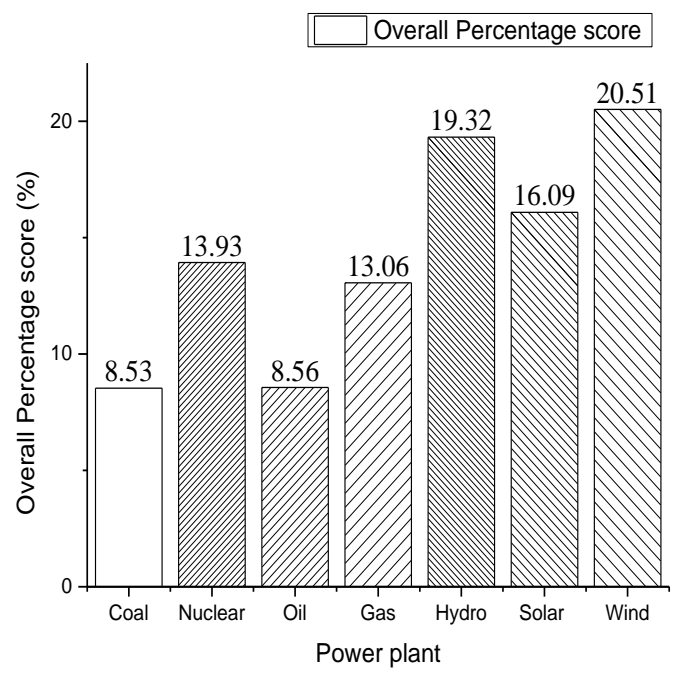

Fig. 2 AHP analysis by Case 1 Global sub-criterion (Equal criteria)

\subsubsection{Case 2 (All sub-criteria is of the same weight)}

In this case of analysis, all the sub-criteria's weight is regarded as same and they are $9.09 \%$ each for every eleven subcriteria. The result shows that hydro is the most beneficial source if all the sub-criteria are taken as equal and gas has more advantage than other renewable sources like oil, coal

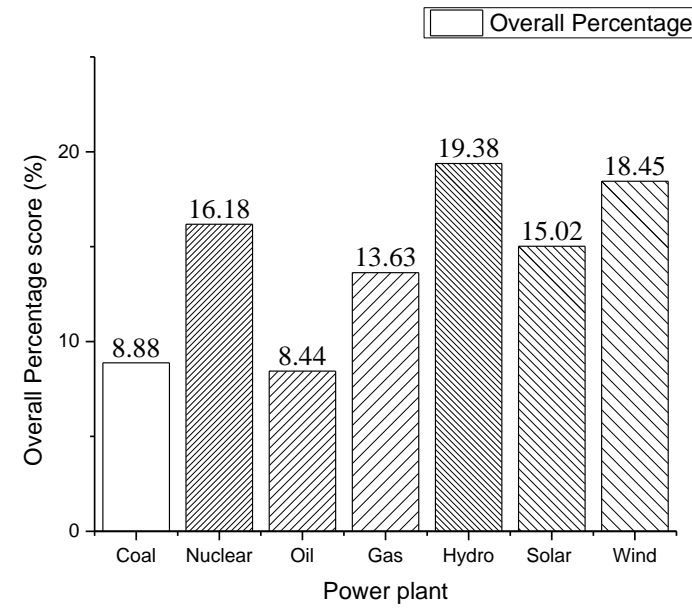

Fig. 3 AHP analysis taking each sub-criterion equal

\subsection{Analysis conditions and results by PROMETHEE}

In PROMETHEE method the result is shown on the Gaia plane with all scatter points. The higher the position in the $y$ axis the more preferable the power plant is. The Gaia plane is a twodimensional plane that shows different point in $x-y$ axis with preferable value.

4.2.1 Case 1 (Global sub-criteria weight for every criterion has equal importance)

The value of global flow was determined for global subcriteria weight by taking each criterion as $33.33 \%$. By the PROMETHEE method analysis, it can be seen that hydropower has the most global flow than other sources. Renewable sources have always the great acceptancy than other sources. Oil has the least amount of acceptancy and nuclear has more acceptancy than coal and oil.

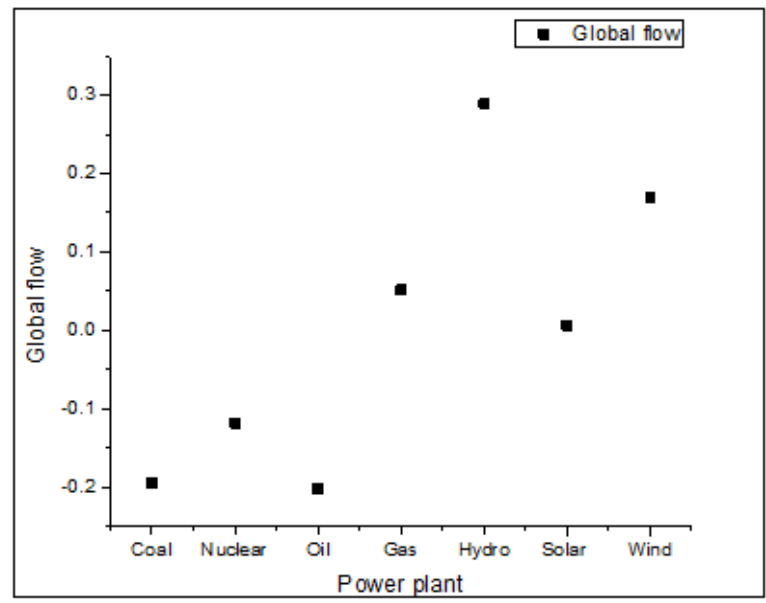

Fig. 4 PROMETHEE analysis by global sub-criteria (Equal criteria)

\subsubsection{Case 2 (All sub-criteria is of same weight)}

As for this every sub-criterion is $9.09 \%$ the global flows show the priority of global flow index for 7 types of power plant. It can be seen that hydro is more efficient than other sources. 


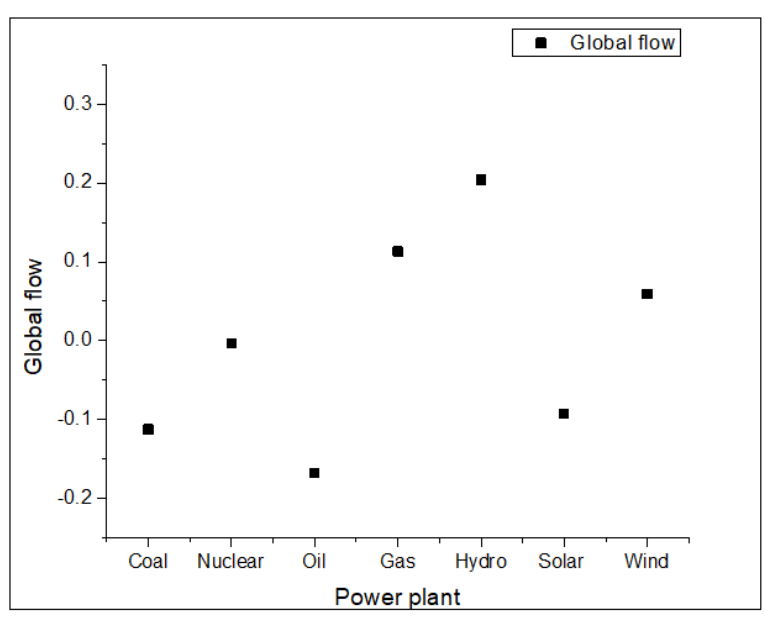

Fig. 5 PROMETHEE analysis taking each sub-criterion equal

4.3 Basic comparison between the AHP and PROMETHEE result

In both AHP and PROMETHEE analysis it has been seen that the renewable sources are better than non-renewable sources and also nuclear has far better sustainability than other sources of non-renewable. From the average result analysis, it can be seen that hydro is the more sustainable source to build and oil is less sustainable source to build. Nuclear power plant plants are much better in case of sustainability.

\section{Conclusion}

Here the sustainability part was defined properly in the case of power plant and the sustainability of a power plant is divided into some criteria and those-criteria is further sub-divided into several sub-criteria and by this, a hierarchy tree was made. Analytical Hierarchy method and PROMETHEE was studied properly and finally the sustainability index was made. By the analysis of seven types of power plants with respect to technology, economy, and safety \& sustainability with the help of the multi-criteria decision analysis for several cases, it can be seen that renewable sources are more sustainable at present. Renewable sources have an endless supply and they can serve as a spontaneous source of energy. Hydro, solar and wind are the highest-ranked power plant in terms of sustainability. The nuclear power plant is also a very beneficial in terms of sustainability and some cases is even more beneficial than renewable sources. Coal has the greatest reserve amongst all the non-renewable fuels analyzed so it can be advantageous too. Gas has an upper hand on coal due to its low capital cost.

\section{References}

[1] World Commission on Environment and Development (WCED). Our Common Future; Oxford University Press: New York, USA, 1987.
[2] Pope, J., Annandale, D. and Morrison-Saunders, A., 2004. Conceptualising sustainability assessment. Environmental Impact Assessment Review, 24(6), pp.595616.

[3] Chatzimouratidis, A.I. and Pilavachi, P.A., 2009. Technological, economic and sustainability evaluation of power plants using the Analytic Hierarchy Process. Energy Policy, 37(3), pp.778-787.

[4] Pons, O. and Aguado, A., 2012. Integrated value model for sustainable assessment applied to technologies used to build schools in Catalonia, Spain. Building and Environment, 53, pp.49-58.

[5] Olson, D.L., 1997. Decision aids for selection problems. Journal of the Operational Research Society, 48(5), pp.541-542.

[6] Brans, J.P. and De Smet, Y., 2016. PROMETHEE methods, Multiple Criteria Decision Analysis (pp. 187219). Springer, New York, NY.

[7] Ranjan, R., Chatterjee, P. and Chakraborty, S., 2016. Performance evaluation of Indian states in tourism using an integrated PROMETHEE-GAIA approach. Opsearch, 53(1), pp.63-84.

[8] Beér, J.M., 2007. High efficiency electric power generation: The environmental role. Progress in Energy and Combustion Science, 33(2), pp.107-134.

[9] University of Washington, Energy Content of Fuels, Hand Out, pp. 1-10, 2005.

[10] Schlomer, S., Bruckner, T., Fulton, L., Hertwich, E., McKinnon, A., Perczyk, D., Roy, J., Schaeffer, R., Sims, R., Smith, P. and Wiser, R., 2014. Annex III: TechnologySpecific Cost and Performance Parameters, Climate Change: Mitigation of Climate Change. Contribution of Working Group III to the Fifth Assessment Report of the Intergovernmental Panel on Climate Change.

[11] EIA, "Electric Power Annual," Eia.Doe.Gov, vol. 0348, no. January, p. 2, 2010.

[12] Ogaji, S.O.T., Sampath, S., Singh, R. and Probert, S.D., 2002. Parameter selection for diagnosing a gas-turbine's performance-deterioration. Applied Energy, 73(1), pp.2546.

[13] Persaud, S., Flynn, D. and Fox, B., 1999. Potential for wind generation on the Guyana coastlands. Renewable Energy, 18(2), pp.175-189.

[14] International Atomic Energy Agency (IAEA),2002. Referance Technology Database.

[15] Spencer, D., 2019. BP Statistical Review of World Energy Statistical Review of World. Ed. BP Stat. Rev. World Energy, 68, pp.1-69.

[16] N. Development, Organisation For Economic CoOperation And Development, no. 6861. 2010.

[17] Cost, E.I.A., 2016. Performance Characteristics of New Generating Technologies. Annual Energy Outlook. 